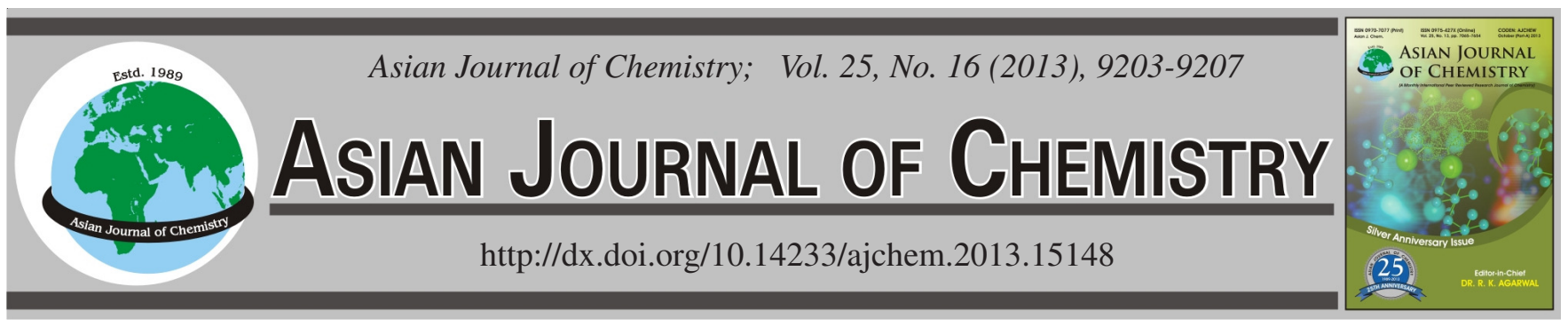

\title{
Investigation on High-Temperature Decomposition and Regeneration Characteristics of Hydroxyapatite Powders and Sinters
}

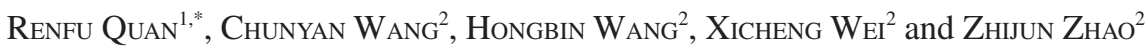

${ }^{1}$ Department of Orthopaedics, Xiaoshan Traditional Chinese Medical Hospital, Hangzhou 311201, P.R. China

${ }^{2}$ School of Materials Science and Engineering, Shanghai University, Shanghai 200072, P.R. China

*Corresponding author: E-mail: quanrenfu8@163.com; rfquan@163.com

(Received: 15 January 2013;

Accepted: 20 September 2013)

AJC-14145

\begin{abstract}
Hydroxyapapite has been widely used because of its excellent biocompatibility. In this work, we studied the decomposition characteristics of both nano-hydroxyapapite powders prepared by the precipitation method and the corresponding sinters at the temperature from room temperature to $1500^{\circ} \mathrm{C}$. X-Ray diffractometer, Raman spectroscopy and high temperature differential scanning calorimeter were employed to investigate the decomposition characteristics. Results show that hydroxyapapite powders gradually release the $\mathrm{OH}^{-}$ions from $1000{ }^{\circ} \mathrm{C}$ and decompose into $\beta$-tricalcium phosphate $(\beta-\mathrm{TCP})$ and tetracalcium phosphate (TTCP) when the heating temperature is higher than $1360{ }^{\circ} \mathrm{C}$ and the $\beta$-TCP phase changes into $\alpha$-TCP at about $1450{ }^{\circ} \mathrm{C}$, which remains if the sinter cools to the room temperature. We also found that the decomposed sinters can reconstitute to hydroxyapapite again under a slow cooling rate and in a certain atmosphere. This work revealed and compared the decomposition and regeneration characteristics of hydroxyapapite powders and sinters, which is useful for the applications of hydroxyapapite materials.
\end{abstract}

Key Words: Hydroxyapatite, Calcium phosphate, Decomposition, Regeneration.

\section{INTRODUCTION}

Hydroxyapatite $\left[\mathrm{Ca}_{10}\left(\mathrm{PO}_{4}\right)_{6}(\mathrm{OH})_{2}\right]$, the main mineral constituent of human bone, is widely investigated for clinical applications because of the excellent biocompatibility, fast bone regeneration ability and direct bonding to regenerated bone without intermediate connective tissue ${ }^{1-4}$. Various bioceramics materials based on hydroxyapapite such as ordered macroporous hydroxyapapite have been reported ${ }^{5}$, which may find applications in fields such as bone regeneration because of their interconnected porosity like other ordered porous materials ${ }^{6}$. However, it is generally accepted that the thermal stability and mechanical properties of hydroxyapapite cannot fully satisfy the requirements of clinical applications ${ }^{7,8}$. To this end, surface coatings by spraying or forming composite materials have been applied to hydroxyapapite ${ }^{9}$. For example, Wen and Kung ${ }^{10}$ developed high quality hydroxyapapite coated polyether ether ketone composites by gas plasma spray. Two different types of hydroxyapapite powders were used in the plasma spray system and they found that the smaller and spherical hydroxyapapite powder produced hydroxyapapite coating with lower surface roughness. A suitable buffer layer such as Ti deposition has been quite effective in improving the hydroxyapatite coating quality, which was ascribed to the improved wettability and heat conductivity. It should be noted that the processing temperature in these treatments is usually higher than the decomposition temperature of hydroxyapapite, leading to the decomposition or transformation of hydroxyapatite. For example, hydroxyapapite can transform to tricalcium phosphate $\left[\mathrm{Ca}_{3}\left(\mathrm{PO}_{4}\right)_{2}\right.$, TCP] or oxyhydroxyapatite $\left[\mathrm{Ca}_{10}\left(\mathrm{PO}_{4}\right)_{6}(\mathrm{OH})_{2}\right]$ at elevated temperature ${ }^{11}$. Previously we employed pressure-less sintering method to prepare $\mathrm{ZrO}_{2} /$ hydroxyapapite composite ceramics at $1600{ }^{\circ} \mathrm{C}$ and found that the decomposition phase on the surface was TCP and tetracalcium phosphate $\left(\mathrm{Ca}_{4} \mathrm{P}_{2} \mathrm{O}_{9}, \text { TTCP }\right)^{12}$. The decomposition of hydroxyapapite at high temperature have hampered its large scale applications as coatings or composite materials.

It is important to investigate the decomposition behaviours of hydroxyapapite. Liao et al. ${ }^{11}$ studied the thermal decomposition and reconstitution of hydroxyapatite powder and confirmed the decomposition temperature of hydroxyapapite powder. Lin et al..$^{13}$ also observed the reconstitution behavior of quenched hydroxyapatite powder and they found that the quenched hydroxyapatite powder could be partly transformed to hydroxyapatite in the air again ${ }^{13}$. Few researchers have studied the decomposition of hydroxyapatite block and sinters and compared with hydroxyapatite powder, which are important for the actual applications. In this work, we investigated and compared the high-temperature decomposition and regeneration characteristics of both hydroxyapatite powders and sinters. 


\section{EXPERIMENTAL}

$\mathrm{Ca}\left(\mathrm{NO}_{3}\right)_{2} \cdot 4 \mathrm{H}_{2} \mathrm{O}$ and $\left(\mathrm{NH}_{4}\right)_{3} \mathrm{PO}_{4} \cdot 3 \mathrm{H}_{2} \mathrm{O}$, as raw materials of analytical grade, were used to prepare nano-hydroxyapatite powders by the method of precipitation ${ }^{14}$. The resultant nano-hydroxyapatite powers was drying for about $3 \mathrm{~h}$ at 110 ${ }^{\circ} \mathrm{C}$ in a DHG-9070 drying cabinet before use. High resolution transmission electron microscope (JEM-2010F, TEM) was employed to observe the morphology of the hydroxyapatite powers.

The hydroxyapatite block with a diameter of $18.9 \mathrm{~mm}$ was formed by pressing on a CMT-530 type universal tester under a pressure of $100 \mathrm{MPa}$ at room temperature. The loading rate was $200 \mathrm{~N} / \mathrm{s}$. The specimen was kept for $180 \mathrm{~s}$ under the maximum pressure and then was put into YFA12/16G-Y chamber electric resistance furnace and sintered at different temperatures in the air.

To study the regeneration behaviour, a hydroxyapatite block was erected in a home-made closed box containing $\mathrm{NaHCO}_{3}(0.5 \mathrm{~g}$ and $1 \mathrm{~g})$. The regeneration reaction box was heated at $900{ }^{\circ} \mathrm{C}$ for $1 \mathrm{~h}$ followed by cooling to room temperature. During the regeneration, the box was sealed with refractory clay and asbestos, so that the decomposition products $\left(\mathrm{CO}_{2}\right.$ and water vapor) of $\mathrm{NaHCO}_{3}$ were able to contact fully with the hydroxyapatite block.

$\mathrm{D} \backslash \max$-2550 X-ray diffractometer (XRD) with $\mathrm{CuK}_{\alpha}$ radiation was employed to detect the crystalline structure of hydroxyapatite power and its sinters. The range of scanning angle was from $20-40^{\circ}$ with a speed of $4 \% \mathrm{~min}$. Raman spectra was recorded at 400, 700, 750, 800, 900, 1000, 1100, 1200, 1300 and $1350{ }^{\circ} \mathrm{C}$ using HR LabRAM800 high temperature Raman spectroscopy to evaluate the functional group of hydroxyapatite. NETZSCH DSC 404C high temperature differential scanning calorimeter (DSC) was used to study the thermal behaviour of hydroxyapatite. The scanning temperature was from room temperature to up to $1550{ }^{\circ} \mathrm{C}$ with a heating rate of $10^{\circ} \mathrm{C} / \mathrm{min}$ and the gas flow rate is $50 \mathrm{~mL} / \mathrm{min}$.

\section{RESULTS AND DISCUSSION}

Hydroxyapatite (HA) powders were prepared from $\mathrm{Ca}\left(\mathrm{NO}_{3}\right)_{2} \cdot 4 \mathrm{H}_{2} \mathrm{O}$ and $\left(\mathrm{NH}_{4}\right)_{3} \mathrm{PO}_{4} \cdot 3 \mathrm{H}_{2} \mathrm{O}$ by the method of precipitation. Fig. 1 shows TEM micrograph and XRD pattern of the resultant hydroxyapatite powders. It can be seen from Fig. 1(a) that the hydroxyapatite powders are less than 100 $\mathrm{nm}$ in length and are rod-shaped. Fig. 1(b) demonstrates the crystal phase transformation for the nano-hydroxyapatite powders. The diameter of the hydroxyapatite block is 18.9 $\mathrm{mm}$ and it shrank to $13.4 \mathrm{~mm}$ after sintered. The shrinkage rate was ca. $29 \%$.

Fig. 2 is the high-temperature DSC curve of hydroxyapatite powder. A series of peaks can be seen from the curve. It is known that there are two kinds of water in hydroxyapatite that was prepared by the method of precipitation, i.e., the absorbed and the crystallization water. The absorbed water was lost at the temperature of $50-200^{\circ} \mathrm{C}$. When the temperature increases to $200-400{ }^{\circ} \mathrm{C}$, the loss of crystallization water occurred. The exothermic peaks at 720 and $901{ }^{\circ} \mathrm{C}$ are caused by the crystallization process. The huge endothermic peak indicates the loss of $\mathrm{OH}^{-}$ion and the decomposition of
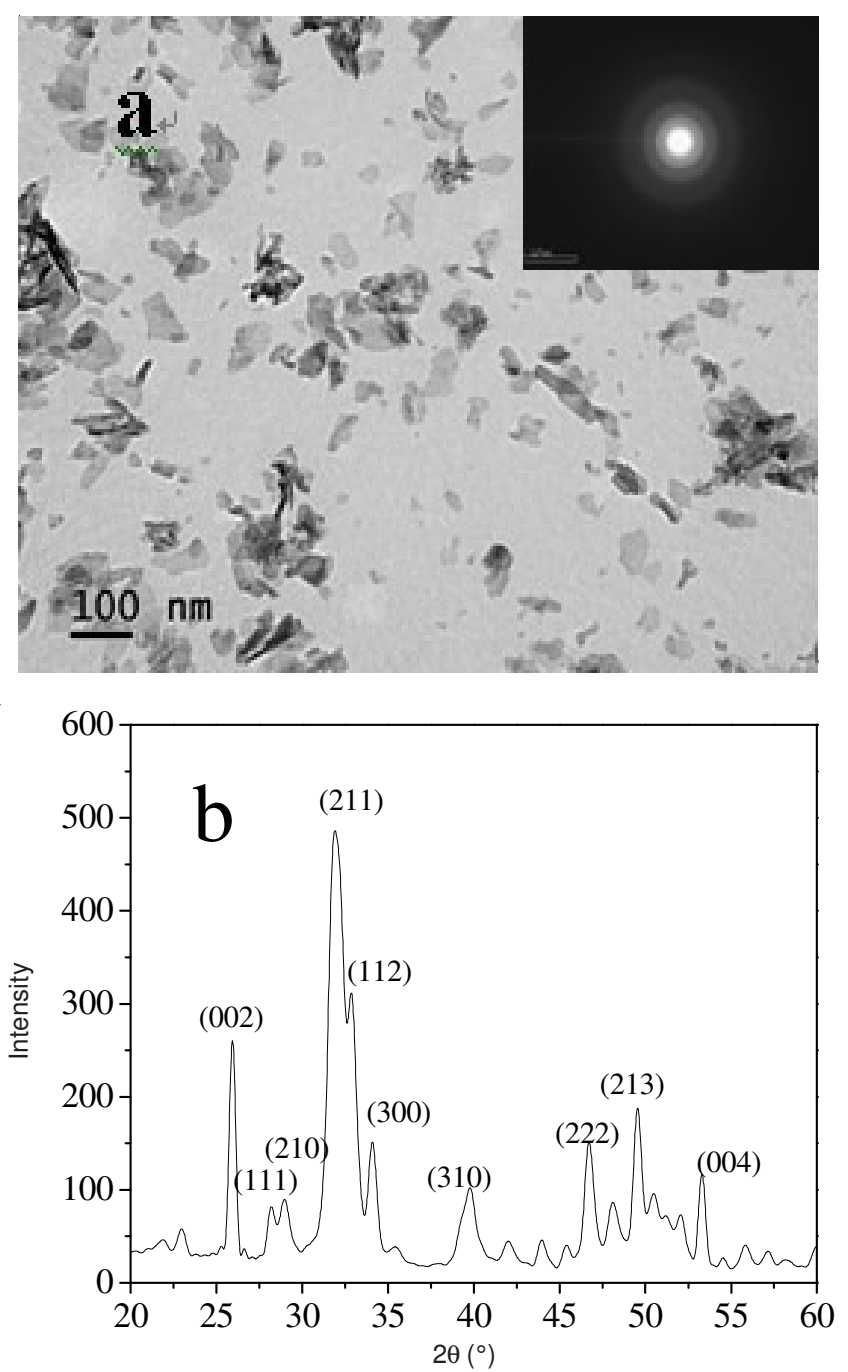

Fig. 1. TEM micrograph (a) and XRD pattern (b) of hydroxyapatite powders

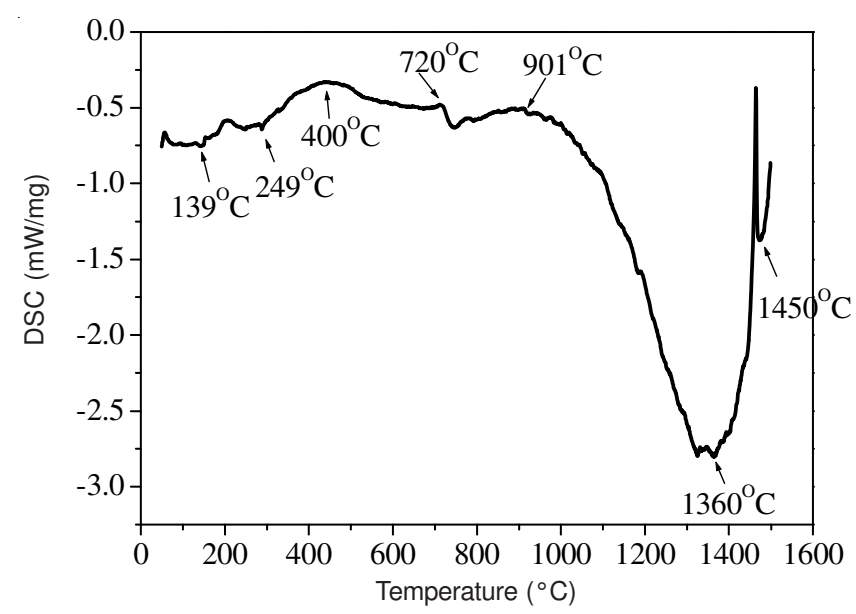

Fig. 2. High-temperature DSC curve of the nano-hydroxyapatite powders

hydroxyapatite. It is believed when the endothermic peak reached the maximum at $1360^{\circ} \mathrm{C}$, hydroxyapatite dehydrates completely and is decomposing. The crystal phase transformation from $\beta$-TCP into $\alpha$-TCP caused the last peak at 1450 ${ }^{\circ} \mathrm{C}^{15}$. Higher decomposition temperature may delay the crystal phase transformation. The decomposition of hydroxyapatite powders can be described by the following equation. 
$\mathrm{Ca}_{10}\left(\mathrm{PO}_{4}\right)_{6}(\mathrm{OH})_{2} \rightarrow 2 \mathrm{Ca}_{3}\left(\mathrm{PO}_{4}\right)_{2}+\mathrm{Ca}_{4} \mathrm{P}_{2} \mathrm{O}_{9}+\mathrm{H}_{2} \mathrm{O}$

The decomposition behavior of the nano-hydroxyapatite powders was also studied by Raman spectroscopy at different temperatures. In Fig. 3, four Raman peaks located at 434, 594, 963 and $1047 \mathrm{~cm}^{-1}$ can be observed. The peak with the strongest intensity at $963 \mathrm{~cm}^{-1}$ is a characteristic peak of hydroxyapatite, corresponding to bond type $\mathrm{v}_{1}(\mathrm{O}-\mathrm{P}-\mathrm{O})$. The other three peaks centered at 434, 594 and $1047 \mathrm{~cm}^{-1}$ are ascribed to $\mathrm{V}_{2}(\mathrm{O}-\mathrm{P}-\mathrm{O})$, $v_{4}(\mathrm{O}-\mathrm{P}-\mathrm{O})$ and $\mathrm{v}_{3}(\mathrm{P}-\mathrm{O})$ bonds, respectively. The peak at 3569 $\mathrm{cm}^{-1}$ represents the characteristic vibrational peak for the hydroxyl group. The peak unfolds with temperature and the relative intensity decreases. Around $1000^{\circ} \mathrm{C}$, the hydroxyl peak disappears completely. This result is consistent with that of DSC (Fig. 2), in which a large endothermic peak appears at $1000{ }^{\circ} \mathrm{C}$ corresponding to its decomposition process. The peak representing $\mathrm{PO}_{4}{ }^{3-}$ is still visible at $1350{ }^{\circ} \mathrm{C}$. Obviously, the decomposition process of hydroxyapatite starts with hydroxyl group, rather than the direct decomposition of the main structure. This fact means the binding capacity of $\mathrm{PO}_{4}{ }^{3-}$ reduces and the system disorder increases. The highest temperature hydroxyapatite remained stable was detected as $1350{ }^{\circ} \mathrm{C}$ by Raman spectroscopy. Table-1 summaries Raman peaks of hydroxyapatite. It can be seen that the key difference between hydroxyapatite and TCP is the presence of hydroxyl group in hydroxyapatite structure. In this work, results reveal that the nano-hydroxyapatite powders contain hydroxyl groups.

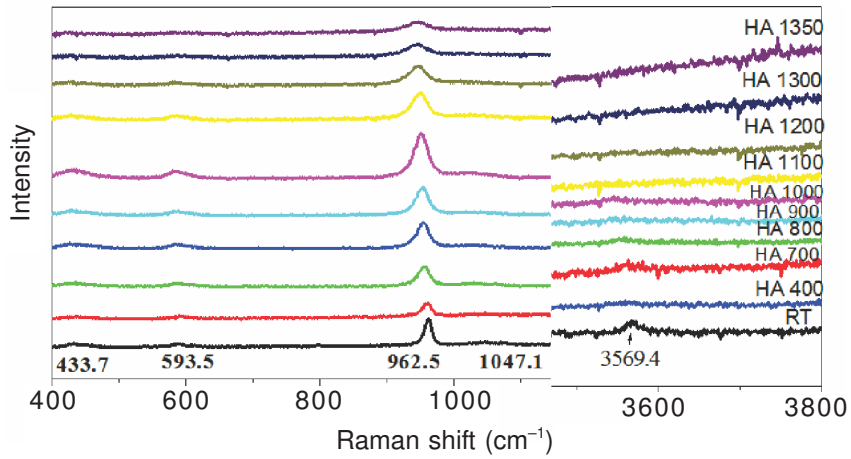

Fig. 3. High-temperature Raman spectra of the nano-hydroxyapatite powders

TABLE-1

RAMAN MODES OF HYDROXYLAPATITE (HA) AND $\alpha$-TCP

\begin{tabular}{lccc}
\hline & $\mathrm{HA}^{[13-16]}$ & $\mathrm{HA}^{-\mathrm{COM}^{[15,16]}}$ & $\alpha-\mathrm{TCP}^{[16]}$ \\
\hline $\mathrm{v}_{2}(\mathrm{O}-\mathrm{P}-\mathrm{O})$ & 432,447 & 432,445 & 420 \\
$\mathrm{v}_{4}(\mathrm{O}-\mathrm{P}-\mathrm{O})$ & $580,593,608$ & $577,590,608$ & 567 \\
$\mathrm{v}_{1}(\mathrm{P}-\mathrm{O}-\mathrm{P})$ & 948,962 & 959 & 938 \\
$\mathrm{v}_{3}(\mathrm{P}-\mathrm{O})$ & $1028,1053,1061,1075$ & $1029,1046,1072$ & 1017 \\
$\mathrm{OH}^{-}$ & 3571 & 3571 & - \\
\hline
\end{tabular}

It is observed that the relative intensity of the Raman peaks first increases and then decreases with the increase of temperature. Moreover, they shift to lower frequency field. As the temperature increases from $400-1000{ }^{\circ} \mathrm{C}$, the crystallinity of nano-hydroxyapatite powders increases and the corresponding peak intensity continuously enhances, which are consistent with the crystallization peaks shown in Fig. 2 by DSC. When the temperature is higher than $1000^{\circ} \mathrm{C}$, the nano-hydroxyapatite powders decompose gradually. As a result, peaks broaden and peak intensity decreases, indicating that the long-range order of hydroxyapatite has been destroyed at that temperature through weakening the intermolecular binding force and loosing the molecular structures.

Raman spectra (Fig. 4) were measured at room temperature and by heating the nano-hydroxyapatite powders to 1500 ${ }^{\circ} \mathrm{C}$ followed by cooling to room temperature. Compared to Fig. 3, the relative strength of $v_{1}(\mathrm{O}-\mathrm{P}-\mathrm{O})$ bond increases, while that of the $v_{3}(\mathrm{P}-\mathrm{O})$ bond decreases. Their peak positions are essentially the same except for slight shift to the higher frequency field. Interestingly, the signal of hydroxyl groups stripped by heating appears again although the peak position slightly varies from 3569 to $3542 \mathrm{~cm}^{-1}$. In addition, for hydroxyapatite cooled to room temperature the peak intensity of hydroxyl groups is lower than that of the original state of hydroxyapatite tested at room temperature. The above results indicate that high-temperature decomposition products of hydroxyapatite regenerate hydroxyl groups during the cooling process. Because the size effect of the nano-hydroxyapatite powder particles, they can fully contact and easily react with the moisture in the air when the furnace is cooling, illustrated by the following equation.

$$
2 \mathrm{Ca}_{3}\left(\mathrm{PO}_{4}\right)_{2}+\mathrm{Ca}_{4} \mathrm{P}_{2} \mathrm{O}_{9}+\mathrm{H}_{2} \mathrm{O} \rightarrow \mathrm{Ca}_{10}\left(\mathrm{PO}_{4}\right)_{6}(\mathrm{OH})_{2}
$$

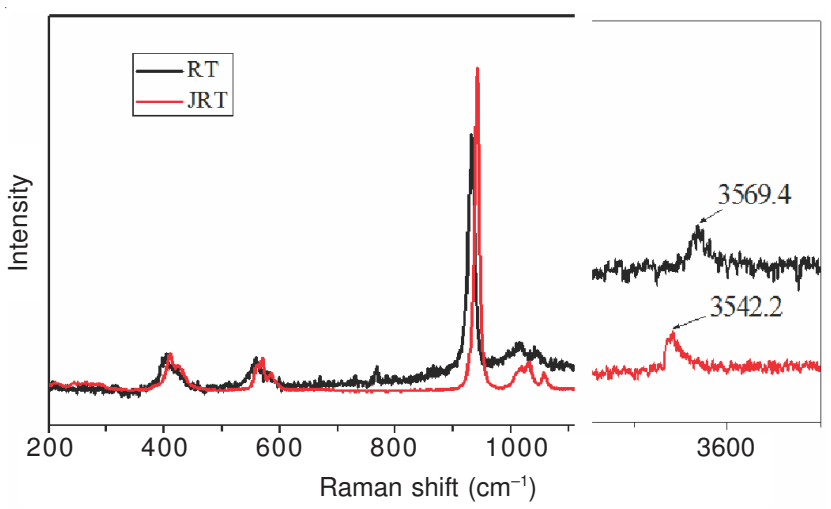

Fig. 4. Raman spectra of nano-hydroxyapatite powders at room temperature (RT: room temperature; JRT: cooling from $1500{ }^{\circ} \mathrm{C}$ to room temperature)

It should be noted that Raman analysis of hydroxyapatite shows that hydroxyapatite decomposition is a reversible or partially reversible process. Therefore, how to take full advantage of the reversible process of hydroxyapatite to reproduce the biological activity of hydroxyapatite-products is clearly a meaningful issue.

Because hydroxyapatite is often applied in medical applications in the forms of block or coating, hydroxyapatite powders and the block after sintering at different temperatures were further analyzed by XRD. The results are shown in Figs. 5 and 6. In Fig. 5, in addition to the labeled $\beta$-TCP peak ( $\beta$ TCP is the doping impurity in the preparation process), the rest peaks are arising from hydroxyapatite characteristic signals. Up to $1350{ }^{\circ} \mathrm{C}$, there is no obvious decomposition of the hydroxyapatite powders. This result is consistent with that from DSC and Raman analysis in this work as well as those reported in literatures ${ }^{11,16}$. From $400-800^{\circ} \mathrm{C}$, the peaks obviously become clear and sharp, indicating the degree of crystallinity gradually becomes higher, which, in turn, supports the crystallization peaks in the DSC curves. 


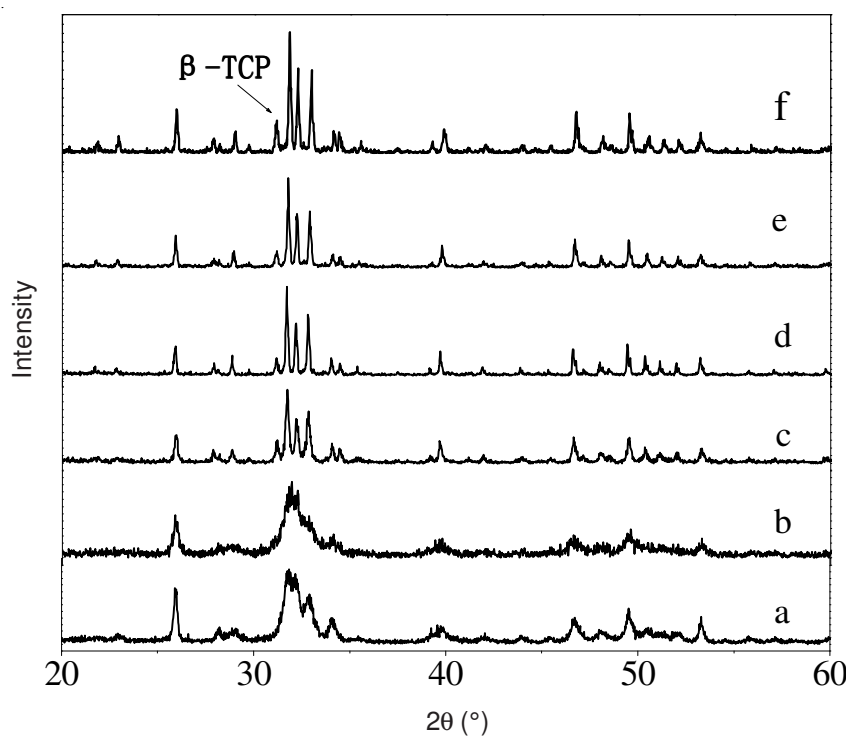

Fig. 5. XRD patterns of the nano-hydroxyapatite powders after sintering (a: original; b: $400{ }^{\circ} \mathrm{C}$; c: $800{ }^{\circ} \mathrm{C}$; d: $1000{ }^{\circ} \mathrm{C}$; e: $1200{ }^{\circ} \mathrm{C}$; f: 1350 $\left.{ }^{\circ} \mathrm{C}\right)$

Fig. 6 shows the XRD patterns of hydroxyapatite powders and the sinters. The products of hydroxyapatite block after sintering at $1500{ }^{\circ} \mathrm{C}$ are composed of $\alpha$-TCP and TTCP. The peaks of the block and the powders sintered at $1300{ }^{\circ} \mathrm{C}$ apparently are offset, which is due to the great pressure subjected by the pressed powder or another possibility that the decomposition temperature of the powder decreases. This phenomenon has not been reported previously and requires further investigation.

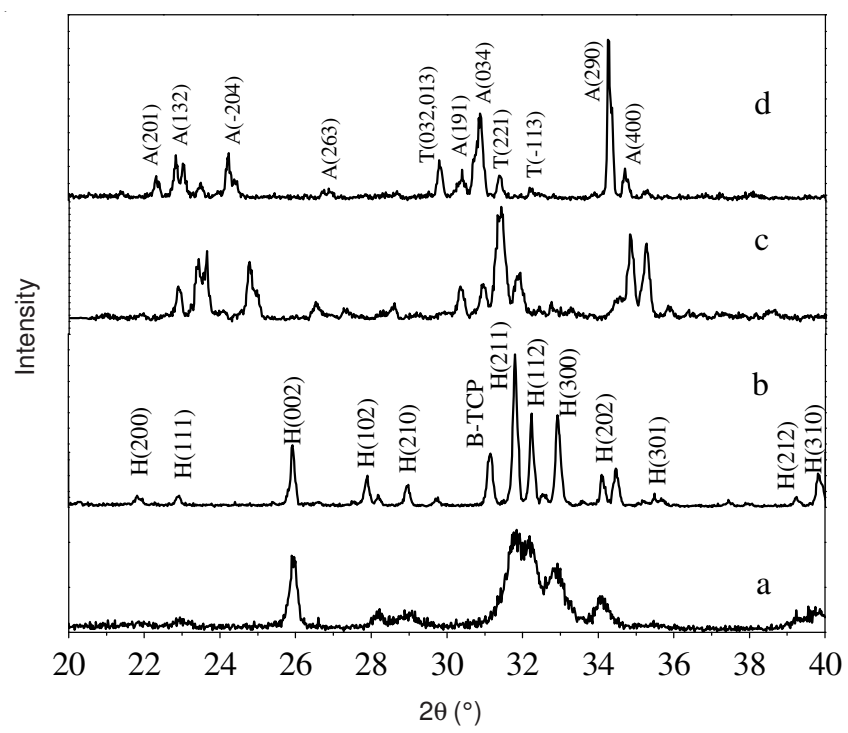

Fig. 6. Contrast of XRD patterns of hydroxyapatite powders and sinters (a: original powders; b: $1300{ }^{\circ} \mathrm{C}$ powders; c: $1300{ }^{\circ} \mathrm{C}$ sinters; $\mathrm{d}$ : $1500{ }^{\circ} \mathrm{C}$ sinters)

We further explored the regeneration possibility of the hydroxyapatite block. The XRD results are shown in Fig. 7, which correspond to hydroxyapatite sinters at room temperature, regenerated at $900{ }^{\circ} \mathrm{C}$ and decomposed. Compared with XRD patterns shown in Fig. 7(a-d) demonstrate that the hydroxyapatite was partially regenerated in the atmosphere

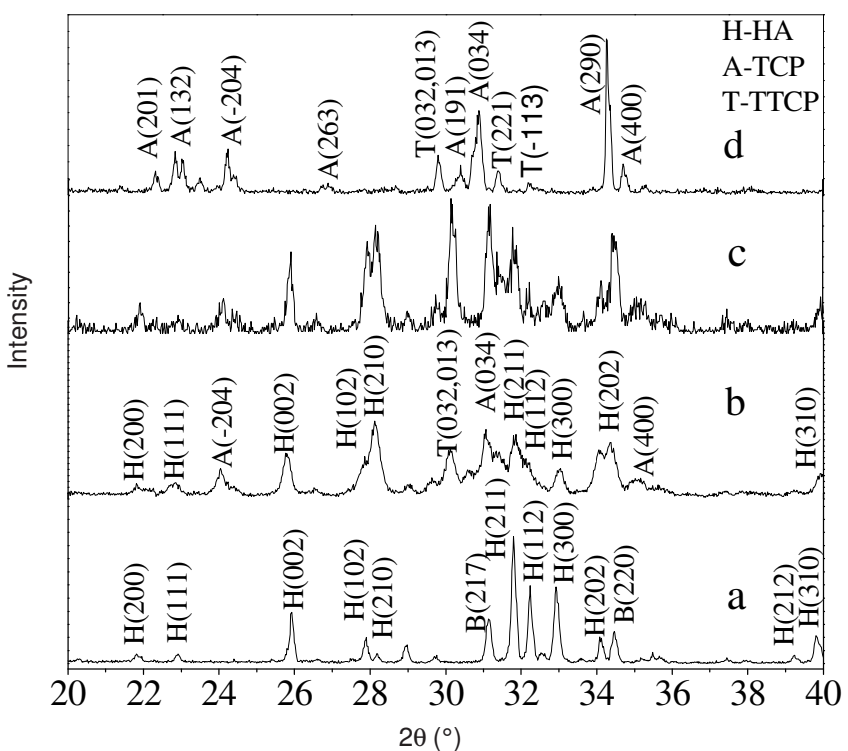

Fig. 7. XRD patterns of reconstructed hydroxyapatite (HA) sinters (a: RT; b: $900{ }^{\circ} \mathrm{C}$ regeneration I; c: $900{ }^{\circ} \mathrm{C}$ regeneration II; d: decomposed sinter)

conditions with addition of $\mathrm{CaO}$ and $\mathrm{Ca}(\mathrm{OH})_{2}$. In Fig. 7(b-c), there are characteristic peaks like (002) (102) (210) (211) (112) (202), but a small amount of $\alpha$-TCP still remains as confirmed by peaks at $(-204)(034)(400)$. This may be related to the tight linkage between particles after being pressed and sintered into bulk which makes it impossible for the regeneration atmosphere to enter into the block. It is known that $\alpha$-TCP can be converted to hydroxyapatite in the following two conditions $^{17-21}$.

$$
\begin{gathered}
3 \mathrm{Ca}_{3}\left(\mathrm{PO}_{4}\right)_{2}+\mathrm{CaO}+\mathrm{H}_{2} \mathrm{O} \rightarrow \mathrm{Ca}_{10}\left(\mathrm{PO}_{4}\right)_{6}(\mathrm{OH})_{2} \\
3 \mathrm{Ca}_{3}\left(\mathrm{PO}_{4}\right)_{2}+\mathrm{Ca}(\mathrm{OH})_{2} \rightarrow \mathrm{Ca}_{10}\left(\mathrm{PO}_{4}\right)_{6}(\mathrm{OH})_{2}
\end{gathered}
$$

Besides, compared to the curve shown in Fig. 7(b), the peak height in Fig. 7(c) is significantly higher, indicating the regeneration yield in sample $\mathrm{c}$ is larger than that in sample $\mathrm{b}$. Regeneration increases with the increase in $\mathrm{CO}_{2}$ and $\mathrm{H}_{2} \mathrm{O}$ content in the atmosphere. Therefore, under suitable atmosphere the regeneration of hydroxyapatite block can occur partially. Combined with the results of regeneration of hydroxyapatite powders, it can be deduced that the regeneration of hydroxyapatite can be considered as a reversible reaction.

\section{Conclusion}

Hydroxyapatite gradually releases its $\mathrm{OH}^{-}$from $1000{ }^{\circ} \mathrm{C}$ and decomposes into $\beta$-TCP and TTCP when the heating temperature is higher than $1350^{\circ} \mathrm{C}$. At $1450{ }^{\circ} \mathrm{C}, \beta$-TCP changes into $\alpha$-TCP which remains if the sinter cools to the room temperature. When the hydroxyapatite sinter slowly cools to room temperature under a suitable atmosphere, the decomposed hydroxyapatite reconstitutes to hydroxyapatite. Heating at $900{ }^{\circ} \mathrm{C}$ for $1 \mathrm{~h}$, the sintered hydroxyapatite can be partially regenerated and the regeneration rate increases with $\mathrm{H}_{2} \mathrm{O}$ content in the atmosphere.

\section{ACKNOWLEDGEMENTS}

The financial support from the Zhejiang Provincial Medical Research Foundation and Science and Technology Development Program of Hangzhou City are gratefully acknowledged. 


\section{REFERENCES}

1. W. Suchanek and M. Yoshimura, J. Mater. Res., 13, 94 (1998).

2. L.M. Sun, C.C. Berndt, K.A. Gross and A. Kucuk, J. Biomed. Mater. Res., 58, 570 (2001).

3. S. Koutsopoulos, J. Biomed. Mater. Res., 62, 600 (2002).

4. K. Mori, T. Hara, T. Mizugaki, K. Ebitani and K. Kaneda, J. Am. Chem. Soc., 126, 10657 (2004).

5. L. Ji, G. Jell, Y. Dong, J.R. Jones and M.M. Stevens, Chem. Commun., 47, 9048 (2011).

6. L.S. Wan, J.W. Li, B.B. Ke and Z.K. Xu, J. Am. Chem. Soc., 134, 95 (2012).

7. A.J. Ruys, M. Wei, C.C. Sorrell, M.R. Dickson, A. Brandwood and B.K. Milthorpe, Biomaterials, 16, 409 (1995).

8. A. Kalaivani, P. Satheeshkumar, G. Senguttuvan, V. Sivakumar and C. S. Dilip, Asian J. Chem., 25, S324 (2013).

9. M.H. Fathi and E.M. Zahrani, J. Alloys Comp., 475, 408 (2009)

10. G.M. Wu, W.D. Hsiao and S.F. Kung, Surf. Coatings Technol., 203, 2755 (2009)

11. C.J. Liao, F.H. Lin, K.S. Chen and J.S. Sun, Biomaterials, 20, 1807 (1999).
12. R. Quan, D. Yang, J. Yan, W. Li, X. Wu and H. Wang, Mater. Sci. Eng. C, 29, 253 (2009).

13. F.-H. Lin, L. Chun-Jen, C. Ko-Shao and S. Jui-Sheng, Mater. Sci. Eng. $C, \mathbf{1 3}, 97$ (2000).

14. M. Huang, J.Q. Feng, J.X. Wang, X.D. Zhang, Y.B. Li and Y.G. Yan, J. Mater. Sci.-Mater. Med., 14, 655 (2003).

15. K. Kandori, S. Mizumoto, S. Toshima, M. Fukusumi and Y. Morisada, J. Phys. Chem. B, 113, 11016 (2009).

16. L. Rintoul, E. Wentrup-Byrne, S. Suzuki and L. Grondahl, J. Mater. Sci.-Mater. Med., 18, 1701 (2007).

17. A.F.L. Almeida, P.B.A. Fechine, J.M. Sasaki, A.P. Ayala, J.C. Goes, D.L. Pontes, W. Margulis and A.S.B. Sombra, Solid State Sci., 6, 267 (2004).

18. C.C. Silva, A.G. Pinheiro, M.A.R. Miranda, J.C. Goes and A.S.B. Sombra, Solid State Sci., 5, 553 (2003).

19. J.L. Xu and K.A. Khor, J. Inorg. Biochem., 101, 187 (2007).

20. H. Li, B.S. Ng, K.A. Khor, P. Cheang and T.W. Clyne, Acta Mater., 52, 445 (2004).

21. F.H. Lin, C.J. Liao, K.S. Chen and J.S. Sun, Mater. Sci. Eng. C, 13, 97 (2000). 